Abstract SAT0223 - Table 1

\begin{tabular}{|c|c|c|c|c|c|c|c|c|}
\hline & \multicolumn{2}{|c|}{$\begin{array}{c}\text { BLISS-52 } \\
\text { IV }(10 \mathrm{mg} / \mathrm{kg})\end{array}$} & \multicolumn{2}{|c|}{$\begin{array}{c}\text { BLISS-76 } \\
\text { IV (10 mg/kg) }\end{array}$} & \multicolumn{2}{|c|}{$\begin{array}{l}\text { North East Asia } \\
\text { IV }(10 \mathrm{mg} / \mathrm{kg})\end{array}$} & \multicolumn{2}{|c|}{$\begin{array}{c}\text { BEL112341 } \\
\text { SC }(200 \mathrm{mg})\end{array}$} \\
\hline & BEL & PBO & BEL & PBO & BEL & PBO & BEL & PBO \\
\hline \multirow[t]{2}{*}{ Baseline characteristics } & \multicolumn{8}{|c|}{$H D A$ subgroup/original $R C T(n / N)$} \\
\hline & $134 / 273$ & $131 / 275$ & $171 / 290$ & $156 / 287$ & $292 / 451$ & $135 / 226$ & $248 / 556$ & $108 / 280$ \\
\hline SELENA-SLEDAI score, mean (SD) & $10.3(3.4)$ & $11.4(4.1)$ & $10.8(4.0)$ & $10.8(3.7)$ & $10.4(3.8)$ & $11.3(4.0)$ & $11.5(3.3)$ & $11.7(3.1)$ \\
\hline SRI response at 52 weeks, \% & 45.5 & 28.2 & 56.1 & 34.6 & 54.0 & 34.1 & 64.6 & 47.2 \\
\hline Outcome at 52 weeks & & & & Odds ratio SC/IV & redibility int & & & \\
\hline HDA criteria & \multicolumn{8}{|c|}{ 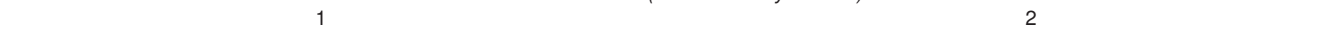 } \\
\hline SRI response & \multicolumn{4}{|c|}{$0.90(0.53,1.52)$} & \multicolumn{4}{|c|}{$0.88(0.58,1.33)$} \\
\hline 4-point reduction in SELENA-SLEDAI & \multicolumn{4}{|c|}{$0.99(0.58,1.68)$} & \multicolumn{4}{|c|}{$0.95(0.63,1.43)$} \\
\hline Rate of severe flares & \multicolumn{4}{|c|}{$0.69(0.37,1.28)$} & \multicolumn{4}{|c|}{$0.89(0.53,1.50)$} \\
\hline
\end{tabular}

patients with active, autoantibody-positive systemic lupus erythematosus (SLE) who are receiving standard SLE therapy has been demonstrated. To date, no direct comparison of intravenous (IV) BEL vs subcutaneous (SC) BEL has been performed, hence the importance of an indirect treatment comparison (ITC).

Objectives: To indirectly compare the clinical effectiveness of BEL IV and SC formulations in patients with SLE high disease activity (HDA) via an ITC

Methods: Three BEL IV Phase III randomised controlled trials (RCTs; HDA/BLISS52, 327/577; HDA/BLISS-76, 265/548; HDA/North East Asia study [BEL113750], 427/677) and one BEL SC RCT (HDA/BEL112341; 356/836) were compared via a Bayesian ITC (BEL207255). We evaluated the relative efficacy of the formulations in patients meeting three measures of HDA at baseline (1. BLISS-52 and BLISS-76, C3 $<0.9 \mathrm{~g} / \mathrm{L}$ or $\mathrm{C} 4<0.16 \mathrm{~g} / \mathrm{L}$; BEL112341 and BEL113750, C3 $<0.9 \mathrm{~g} / \mathrm{L}$ or $\mathrm{C} 4<0.10 \mathrm{~g} / \mathrm{L}$; and 2 . anti-dsDNA positive $[\geq 30 \mathrm{IU} / \mathrm{mL}]$ or 3 . Safety of Estrogen in Lupus Erythematosus National Assessment-SLE Disease Activity Index [SELENA-SLEDAI] scores $>10$ ). Analyses were conducted in patients meeting Criteria 1: low C3/C4 and high anti-dsDNA; and Criteria 2: low C3/C4 and high anti-dsDNA or SELENA-SLEDAI $\geq 10$ or low C3/C4. The primary endpoint was SLE Responder Index (SRI) response ( $\geq 4$-point reduction in SELENASLEDAI, no worsening in Physician's Global Assessment, no new 1A/2B British Isles Lupus Assessment Group domain scores) at Week 52. Secondary endpoints included $\geq 4$-point reduction in SELENA-SLEDAI and SLE Flare Index rate. Safety endpoints were not assessed.

Results: Baseline characteristics were relatively similar between RCTs and a fixed effects model binomial distribution with logit link was used for all efficacy endpoints (Table). In this indirect comparison, no differences were identified between BEL IV and BEL SC for the efficacy endpoints.

Conclusions: In this indirect comparison, BEL IV and BEL SC were similar for $\mathrm{SRI}$ response, $\geq 4$-point reduction in SELENA-SLEDAI, or rate of severe flare at Week 52 in patients with SLE. Outcomes were consistent irrespective of the criteria applied.

Acknowledgements: Study funded by GSK. Katie White, PhD, Fishawack Indicia Ltd, UK, provided editorial assistance funded by GSK.

Disclosure of Interest: D. Parks Shareholder of: GSK, Employee of: GSK, S. Ramachandran Shareholder of: GSK, Employee of: GSK, M. Kurtinecz Employee of: GSK, Y. Asukai Shareholder of: GSK, Employee of: GSK, R. Alfonso-Cristancho Shareholder of: GSK, Employee of: GSK DOI: 10.1136/annrheumdis-2017-eular.4701

\section{SAT0224 THE ROLE OF INTENSIVE IMMUNOSUPPRESSIVE THERAPY IN THE MANAGEMENT OF SLE-ASSOCIATED PULMONARY ARTERIAL HYPERTENSION: A SINGLE-CENTER COHORT STUDY}

Q. Wang ${ }^{1}$, J. Zhao ${ }^{1}$, J. Qian ${ }^{2}$, Z. Tian ${ }^{3}$, M. Li ${ }^{1}$, X. Zeng ${ }^{1} .{ }^{1}$ Rheumatology; ${ }^{2}$ Internal Medicine; ${ }^{3}$ Cardiology, Peking Union Medical College Hospital, Beijing, China

Background: Autoimmune and inflammatory mechanisms could play a significant role in the pathogenesis of pulmonary arterial hypertension (PAH), especially in patients with systemic lupus erythematosus (SLE). The effect of immunosuppressive therapy in the treatment of SLE-associated PAH (SLE-PAH) has not been fully investigated in a large cohort previously.

Objectives: We aimed to review the clinical outcomes in patients with SLE$\mathrm{PAH}$ cohort treated with intensive immunosuppressive therapy with or without PAH-targeted therapy.

Methods: In this single-center cohort study, 126 patients with SLE-PAH were consecutively enrolled between May 2006 through December 2015. All patients were performed right heart catheriazation to confirm the diagnosis of $\mathrm{PAH}$, and all received intensive immunosuppressive therapy including combination of high-dose glucocorticosteroids and immunosuppressants, such as cyclophosphamide, mycophenolate and calcineurin inhibitors. Baseline demographics, clinical features, laboratory findings, hemodynamic measurements and treatment were analyzed. Kaplan-Meier curves and Cox proportional hazards regression analysis were used to evaluate the role of intensive immunosuppressive therapy.

Results: Of the 126 SLE-PAH patients, eighty-two (65.1\%) patients received $\mathrm{PAH}$-targeted therapy at baseline. Demographic and clinical characteristics were shown in Table 1. Survival analysis indicated that responders had a better survival than nonresponders in both with and without PAH-targeted therapy groupPatients with a shorter SLE disease duration $(\mathrm{p}=0.009)$ and better baseline pulmonary hemodynamics (mean pulmonary arterial pressure, pulmonary vascular resistance and Cardiac index, $\mathrm{p}<0.001$ ) were more likely to benefit from immunosuppressive therapy (Table 1)

Table1.Comparison of clinical characteristics in responders and nonresponders to immunosuppressive therapy

\begin{tabular}{lcccccc}
\hline & \multicolumn{3}{c}{ SLE-PAH without target therapy } & \multicolumn{3}{c}{ SLE-PAH with target therapy } \\
& $\begin{array}{c}\text { Responder } \\
\mathrm{N}=29\end{array}$ & $\begin{array}{c}\text { Nonresponder } \\
\mathrm{N}=15\end{array}$ & $p$-value & $\begin{array}{c}\text { Responder } \\
\mathrm{N}=44\end{array}$ & $\begin{array}{c}\text { Nonresponder } \\
\mathrm{N}=38\end{array}$ & $p$-value \\
\hline Female, n, (\%) & $29(100)$ & $15(100)$ & 1.000 & $43(100)$ & $37(97.4)$ & 1.000 \\
Age, years & $33.8 \pm 9.2$ & $37.0 \pm 10.0$ & 0.293 & $32.1 \pm 7.2$ & $35.3 \pm 8.3$ & 0.066 \\
SLE Disease & $3.5(0,23.7)$ & $6.4(1.0,33.1)$ & 0.090 & $4.8(0,18.9)$ & $6.3(0.7,23.1)$ & 0.427 \\
duration, months & $19(65.5)$ & $9(60.0)$ & 0.718 & $24(54.5)$ & $24(63.2)$ & 0.430 \\
RP,n(\%) & & & & & & \\
Anti-u1RNP, & $21(72.4)$ & $10(66.7)$ & 0.676 & $25(61.0)$ & $19(50.0)$ & 0.326 \\
n (\%) & $7.0 \pm 6.2$ & $5.1 \pm 4.5$ & 0.296 & $3.0 \pm 2.9$ & $3.5 \pm 2.6$ & 0.420 \\
SLEDAl-2000 & & & & & \\
WHO functional classification & & & & & \\
I-III, n(\%) & $17(58.6)$ & $5(33.3)$ & 0.013 & $21(47.7)$ & $18(47.6)$ & 0.292 \\
$\quad$ III-IV, n(\%) & $12(41.4)$ & $10(66.7)$ & & $23(52.3)$ & $20(52.6)$ & \\
6MWD, meter & $465.3 \pm 77.4$ & $424.0 \pm 97.9$ & 0.180 & $417.8 \pm 99.4$ & $398.2 \pm 92.9$ & 0.409 \\
Mean RAP, mmHg & $4.2 \pm 3.0$ & $2.8 \pm 2.8$ & 0.201 & $3.9 \pm 4.3$ & $4.3 \pm 4.0$ & 0.706 \\
Mean PAP, mmHg & $37.9 \pm 8.2$ & $45.7 \pm 7.9$ & 0.005 & $45.1 \pm 10.3$ & $53.2 \pm 11.0$ & 0.001 \\
CI, I.min ${ }^{-1} \cdot \mathrm{m}^{-2}$ & $3.2 \pm 0.7$ & $2.5 \pm 0.6$ & 0.003 & $2.8 \pm 0.6$ & $2.4 \pm 0.8$ & 0.018 \\
PVR, WU & $6.6 \pm 2.4$ & $10.5 \pm 3.0$ & 0.001 & $9.2 \pm 3.6$ & $12.7 \pm 4.5$ & 0.000
\end{tabular}

Conclusions: Intensive immunosuppressive therapy markedly improved the long-term outcomes of SLE patients with $\mathrm{PAH}$, especially in the early stage of $\mathrm{PAH}$.

References:

[1] Chung L, Liu J, Parsons L, et al. Characterization of connective tissue disease-associated pulmonary arterial hypertension from REVEAL: identifying systemic sclerosis as a unique phenotype. Chest, 2010; 138:1383-94.

[2] Shirai $Y$, Yasuoka H, Okano $Y$, Takeuchi T, Satoh $T$ and Kuwana M Clinical characteristics and survival of Japanese patients with connective tissue disease and pulmonary arterial hypertension: a single-centre cohort. Rheumatology (Oxford), 2012; 51:1846-54.

[3] Kang $\mathrm{KY}$, Jeon $\mathrm{CH}$, Choi SJ, et al. Survival and prognostic factors in patients with connective tissue disease-associated pulmonary hypertension by echocardiography: results from a Korean nationwide registry. Int J Rheum Dis, 2015.

[4] Miyamichi-Yamamoto S, Fukumoto Y, Sugimura K, et al. Intensive immunosuppressive therapy improves pulmonary hemodynamics and long-term prognosis in patients with pulmonary arterial hypertension associated with connective tissue disease. Circ J, 2011; 75:2668-74.

[5] Price LC, Wort SJ, Perros F, et al. Inflammation in pulmonary arterial hypertension. Chest, 2012; 141:210-21.

Disclosure of Interest: None declared

DOI: 10.1136/annrheumdis-2017-eular.6594

\section{SAT0225 CEREBLON MODULATOR CC-220 DECREASES NAÏVE AND MEMORY B CELLS AND PLASMACYTOID DENDRITIC CELLS IN SYSTEMIC LUPUS ERYTHEMATOSUS (SLE) PATIENTS: EXPOSURE-RESPONSE RESULTS FROM A PHASE 2A PROOF OF CONCEPT STUDY}

A. Gaudy ${ }^{1}$, Y. Ye ${ }^{1}$, S. Korish ${ }^{1}$, D. Hough ${ }^{1}$, M. Weiswasser ${ }^{1}$, S. Choi ${ }^{1}$

R. Furie ${ }^{2}$, V. Werth ${ }^{3}$, P. Schafer ${ }^{1} .{ }^{1}$ Celgene Corporation, Summit, NJ;

${ }^{2}$ Northwell Health, Great Neck, NY; ${ }^{3}$ University of Pennsylvania and the VA Medical Center, Philadelphia, PA, United States

Background: CC-220 is a cereblon E3 ligase modulatory compound currently in development for the treatment of Systemic Lupus Erythematosus as well as other autoimmune conditions and multiple myeloma. As a high affinity ligand for cereblon, CC-220 administration results in significant reductions in ikaros (IKZF1) and aiolos (IKZF3), transcription factors which are genetically linked to SLE risk, and are overexpressed in the peripheral blood of SLE patients compared to healthy controls.

Objectives: To describe the pharmacokinetics (PK), pharmacodynamics (PD) and the PK-PD relationship of CC-220 in subjects with SLE.

Methods: CC-220-SLE-001 is a randomized, double-blinded, placebo-controlled, 
phase 2a dose escalation study to investigate the safety, PK, PD, and efficacy of CC-220 in patients with SLE. Forty-two (42) adult SLE subjects fulfilling SLE ACR criteria, having a history of SLE for $\geq 6$ months and a baseline Safety of Estrogens in Lupus Erythematosus National Assessment-Systemic Lupus Erythematosus Disease Activity Index (SELENA-SLEDAI) score $\geq 4$ were randomized to placebo or 1 of 4 escalating doses of CC-220 $(0.3 \mathrm{mg} \mathrm{QOD}, 0.3 \mathrm{mg} \mathrm{QD}, 0.6 / 0.3 \mathrm{mg}$ alternating $\mathrm{QD}$, or $0.6 \mathrm{mg} \mathrm{QD)}$.

Results: CC-220 concentration-time profiles demonstrated dose proportionality between cohorts, with moderate accumulation in the non-alternating dose cohort. CC-220 significantly reduced total CD20+ B cells by as much as $96 \%$, immature B cells by as much as $91.2 \%$, switched memory B cells by as much as $81.4 \%$, BAFFR+ B cells by as much as $67.5 \%$, and plasmacytoid dendritic cells (pDCs) by as much as $86.5 \%$ (Day 85 median percent change from baseline). Whereas reductions in B cells were observed, CD4+ as well as CD8+ T cells increased, and the rise in $T$ cells paralleled the observed increase in plasma cells in those subjects who received the highest dose $(0.6 \mathrm{mg})$. An exposure-response analysis demonstrated decreasing $B$ cells, pDCs and neutrophils with increased exposure to CC-220.

Conclusions: It was determined that $0.3 \mathrm{mg} \mathrm{QD}$ to $0.6 / 0.3 \mathrm{mg}$ alternating $\mathrm{QD}$ reduced concentrations of $\mathrm{B}$ cells and pDC's while avoiding neutropenia. These findings, in combination with the PK, safety, and exploratory efficacy data, support continued development of CC-220 in SLE.

Disclosure of Interest: A. Gaudy Shareholder of: Celgene, Employee of: Celgene, Y. Ye Shareholder of: Celgene, Employee of: Celgene, S. Korish Shareholder of: Celgene, Employee of: Celgene, D. Hough Shareholder of: Celgene, Employee of: Celgene, M. Weiswasser Shareholder of: Celgene, Employee of: Celgene, S. Choi Shareholder of: Celgene, Employee of: Celgene, R. Furie Consultant for: Celgene, V. Werth Grant/research support from: Celgene, Consultant for: Celgene, P. Schafer Shareholder of: Celgene, Employee of: Celgene

DOI: 10.1136/annrheumdis-2017-eular.3036

\section{SAT0226 A FIRST-IN-HUMAN, STUDY OF BMS-986165, A SELECTIVE, POTENT, ALLOSTERIC SMALL MOLECULE INHIBITOR OF TYROSINE KINASE 2}

I. Catlett ${ }^{1}$, U. Aras $^{2}$, Y. Liu ${ }^{3}$, D. Bei ${ }^{2}$, I. Girgis ${ }^{2}$, B. Murthy ${ }^{2}$, M. Honczarenko ${ }^{1}$ S. Rose ${ }^{1} .{ }^{1}$ Innovative Clinical Development; ${ }^{2}$ Clinical Pharmacology; ${ }^{3}$ Global Biometric Sciences, Bristol-Myers Squibb, Princeton, United States

Background: Tyrosine kinase 2 (Tyk2) is a member of the JAK family that phosphorylates STAT proteins downstream of the IL-12, IL-23 and the Type I interferon receptor. Tyk2 genetic variants have been linked to multiple autoimmune diseases, ${ }^{1}$ with a deactivating coding variant conferring significant protection against multiple immune-mediated disorders including systemic lupus erythematosus (SLE). ${ }^{2}$ Selective pharmacologic inhibition of Tyk2 has proven daunting, given the high degree of similarity among JAK catalytic domains. Using a novel approach, we have developed BMS-986165, a highly selective and potent small molecule inhibitor, which blocks receptor-mediated Tyk2 activation by stabilizing the regulatory pseudokinase domain of the protein. Lupus-like disease is strongly inhibited in NZB/W mice treated with BMS-986165. Together, these data establish Tyk2 as a highly promising therapeutic target for SLE.

Objectives: We report the first evidence of safety, pharmacokinetics (PK), target engagement (TE), and pharmacodynamic activity (PD) of BMS-986165, a novel inhibitor of Tyk2.

Methods: Safety, PK, TE, and PD were assessed in a randomized, double-blind, single and multiple ascending dose study of 108 ( 83 active: 25 placebo) healthy participants (NCT02534636). Target engagement was assessed by an ex vivo assay, IL-12 and IL-18 induced IFN $\gamma$ production. Roferon-A was administered to assess in vivo pharmacodynamic effects of BMS-986165 on physiological manifestations of IFN exposure and on IFN-regulated gene (IRG) expression.

Results: BMS-986165 was safe and overall well-tolerated. There were no serious adverse events and the frequency of non-serious adverse events were similar in the active $(75 \%)$ and placebo $(76 \%)$ groups. The most frequently reported adverse events by preferred term were headache $(23 \%$ active versus $28 \%$ placebo), nausea (12\% active versus $8 \%$ placebo), rash (12\% active versus $8 \%$ placebo), and upper respiratory tract infection ( $11 \%$ active versus $12 \%$ placebo). After oral administration, BMS-986165 was rapidly absorbed and exhibited an apparent elimination half-life of $8-15$ hours. Modest accumulation $(1.4 x-1.9 x)$ was observed after multiple dosing. BMS-986165 inhibited IL-12/IL-18-induced IFN $\gamma$ production in ex vivo assays in a dose and concentration dependent manner. Following an in vivo challenge with a clinical dose of Interferon-alfa-2A, BMS986165 demonstrated dose-dependent inhibition of lymphocyte count decreases and expression of 53 IRGs in blood (Figure 1).

Conclusions: BMS-986165 is a safe and potent Tyk2 inhibitor with clear evidence of ex vivo and in vivo biologic activity in healthy participants, and the potential for once daily dosing. Overall, Inhibition of IL-12/23 and type I IFN pathways support further testing of BMS-986165 in diseases such as lupus and psoriasis. A Phase 2 study in patients with moderate-to-severe psoriasis is ongoing (NCT02931838). References:

[1] Liang Y, Zhu Y, Xia Y, Peng H, Yang XK, et al. Therapeutic potential of tyrosine kinase 2 in autoimmunity. Expert Opin Ther Targets. 2014 May;18(5):57180.

[2] Dendrou CA, Cortes A, Shipman L, Evans HG, Attfield KE, et al. Resolving
Figure 1: In vivo pharmacodynamic challenge
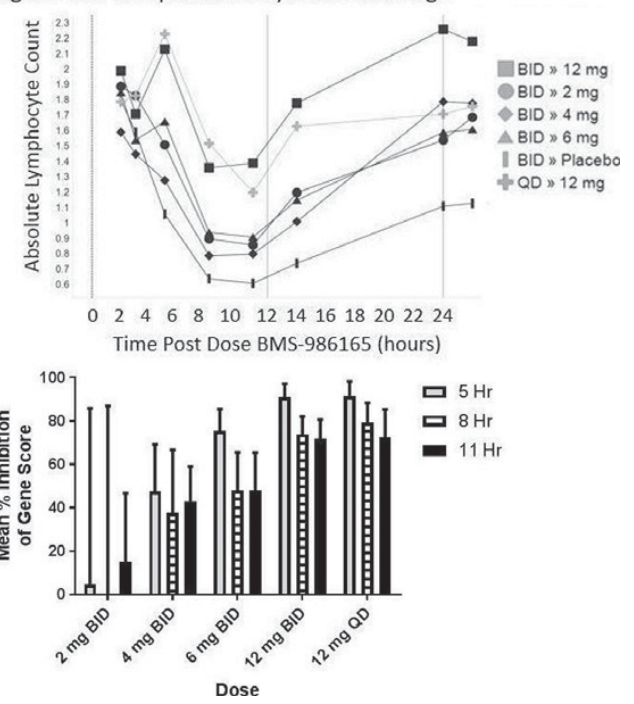

TYK2 locus genotype-to-phenotype differences in autoimmunity. Sci Transl Med. 2016 Nov 2;8(363):363ra149.

Disclosure of Interest: I. Catlett Shareholder of: Bristol-Myers Squibb, Employee of: Bristol-Myers Squibb, U. Aras Shareholder of: Bristol-Myers Squibb, Employee of: Bristol-Myers Squibb, Y. Liu Shareholder of: Bristol-Myers Squibb, Employee of: Bristol-Myers Squibb, D. Bei Shareholder of: Bristol-Myers Squibb, Employee of: Bristol-Myers Squibb, I. Girgis Shareholder of: Bristol-Myers Squibb, Employee of: Bristol-Myers Squibb, B. Murthy Shareholder of: Bristol-Myers Squibb, Employee of: Bristol-Myers Squibb, M. Honczarenko Shareholder of: Bristol-Myers Squibb, Employee of: Bristol-Myers Squibb, S. Rose Shareholder of: Bristol-Myers Squibb, Employee of: Bristol-Myers Squibb

DOI: 10.1136/annrheumdis-2017-eular.3809

\section{SAT0227 HEALTH CARE UTILIZATION AND COSTS OF SYSTEMIC LUPUS ERYTHEMATOSUS (SLE) IN THE UNITED STATES: SYSTEMATIC REVIEW}

E. Hammond ${ }^{1}$, I.B. Murimi ${ }^{2}$, D.H. Lin ${ }^{2}$, H. Kan ${ }^{2}$, J. Tierce ${ }^{2}$, X. Wang ${ }^{1}$, H. Nab ${ }^{3}$, B. Desta ${ }^{1}$, G.C. Alexander ${ }^{2} .{ }^{1}$ AstraZeneca, Gaithersburg, MD; ${ }^{2}$ Johns Hopkins Bloomberg School of Public Health, Baltimore, MD, United States; ${ }^{3}$ AstraZeneca, Cambridge, United Kingdom

Background: Systemic lupus erythematosus (SLE) is a chronic autoimmune disease that affects as many as 518 persons per 100,000 people in the United States and Europe.

However, much of our current knowledge on SLE health care utilization and costs is based on analyses conducted prior to 2011, after which important treatment innovations (e.g., belimumab and, to some extent, rituximab) and health care marketplace changes occurred in the United States.

Objectives: The objectives of this systematic review were to summarize the patterns of health care utilization for patients with SLE and to characterize the direct and indirect costs of SLE by disease severity in the United States.

Methods: We conducted a systematic literature review of adult patients with SLE in the United States by searching PubMed and Embase for relevant articles written in English and published during January 2000-April 2016. We examined health care utilization measures including emergency department (ED) visits, hospitalizations, outpatient visits, medication use, and adherence. We restricted the analysis to observational studies, excluding case reports and commentaries. All monetary costs were converted to US 2016 \$.

Results: In total, 4,700 articles were screened, 388 articles were retained for full-text review, and 38 articles were selected for inclusion in this report. Across these 38 studies, mean patient ED utilization rates were 0.9-2.1 visits/year. Mean hospitalization rates were 0.4-2.6 inpatient stays/year, with 5-6 days/stay on average. Patients averaged 10-19 total physician visits/year. More than $90 \%$ of patients with SLE had $\geq 1$ visit to a primary care provider annually. In addition, $51-71 \%$ visited rheumatologists, and $6-7 \%$ visited nephrologists. Health care resource use with respect to ED visits, hospitalization rates, inpatient length of stay, and ambulatory care was greater for patients with lupus nephritis than for patients with SLE without nephritis. Mean annual direct costs from various studies ranged between $\$ 15,171-88,445$ for patients with SLE regardless of the presence of nephritis. Nearly all studies indicated that mean direct medical costs were greater for patients with moderate or severe disease $(\$ 22,300-83,000)$ than those with mild disease $(\$ 8,900-15,000)$. Mean annual pharmacy costs ranged between $\$ 1,572-13,138$, accounting for $19-23 \%$ of total direct costs, and medical costs ranged between $\$ 21,290-82,854$. On average, $12-49 \%$ of patients were unemployed, and the mean number of sick days/month was 2.3 days. The range of estimates of mean total direct costs for patients with SLE overall were often 